\title{
Design of Bias Power Supply for Magnetron Sputtering with Automatic Equalization Current
}

\author{
Xiping HUANG*, Guitao CHEN, Yanlin NIE \\ Xi'an University of Technology \\ Xi'an 710048, Shanxi ,China \\ *E-mail: huangxp@xaut.edu.cn \\ $+*$ Corresponding author
}

\begin{abstract}
High power switching power supply with modularization faces the challenges of equalizing voltage and current between each module. It is difficult to guarantee the reliable equalizing current by controlled equalizing current method while the large current is changing in the arc process of magnetron sputtering. A high power BPSMS based on the input parallel output parallel phase shifted full bridge converter (IPOP-PSFB) was developed. The power supply could realize AEC via the transformer secondary side crossed rectification without adding additional control strategy. The operating mode of the main circuit and the steady-state equalizing current principle were analyzed. Finally, a $20 \mathrm{~kW}$ experimental prototype was designed to verify the effect of AEC.
\end{abstract}

Keywords-Bias power supply for magnetron sputtering (BPSMS); Combined full bridge; Crossed rectification; Automatic equalization current (AEC)

\section{INTRODUCTION}

Magnetron sputtering ion plating technology, with the advantages of low substrate temperature, high deposition rate and good adhesion strength is widely used in the treatment of material surfaces. With the increase of vacuum chamber and target area, BPSMS, which is composed of a single converter, is difficult to meet the industrial demand. Series and parallel connection between internal device of converter and series and parallel of independent power supply module have become the main development trends. The problem of equalizing voltage and current aroused.

IPOP combined converter mostly includes a full-bridge converter or a half-bridge converter. These converters have the properties of a Buck converter. The output characteristic of Buck working in CCM mode is equivalent to a voltage source which consists of a series of an ideal voltage source $\mathrm{Vi}$ and a small value resistance $\mathrm{Rj}$ [1]. Due to the parameter difference, the output current of each module cannot be equalized. Now, the more mature control methods are droop method, active method and so on[2].However, they increase the difficulty and cost. AEC method can realize the equalizing current by changing the converter topology without complex control methods, and it has the characteristic of high stability and low cost[3]. There is a load mutation of plasma load during starting process and the arc discharge phenomenon, the stability and fast response of bias power supply are very important [4]. The method of control equalizing current cannot carry on equalizing current reliably for the short time and large current plasma discharge condition. It may lead to a single module excessive current. In this paper, AEC method on crossed rectification was studied for bias power supply, which can be fast and steady equalizing current

\section{DESIGN OF MAIN CIRCUIT}

PSFB was used as the basic module of BPSMS. The soft switch was used to improve the power supply efficiency and reliability. The power level was increased through parallel. The crossed rectification was adopted in the secondary side of transformer, as shown in Fig.1, The rectified output of two half wave cycle of plus and minus in the same module was connected to different output filter inductance[5]. There was a blocking capacitor in the secondary side, in order to ensure each module equalizing output current when there were parameter differences.

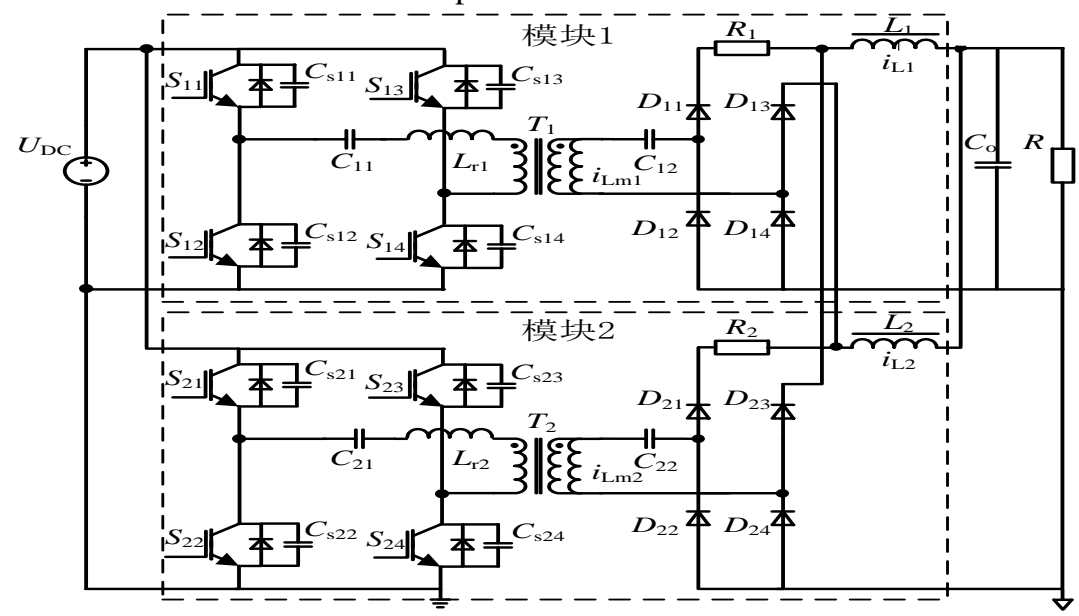

Figure 1. IPOP-PSFB main circuit of secondary side crossed rectifier 
A. Analysis of Operation Modes of the Circuit with the Same Duty Cycle(SDC)

The operation time sequence of the switch tube for module 1 and 2 were exactly the same. There was a 1800 difference of driving pulse between leading leg $S_{11}$ and $S_{12}$, The same for lagging leg $\mathrm{S}_{13}$ and $\mathrm{S}_{14}$. PSFB was controlled by adjusting the driving pulse open time of lagging leg. The PSFB-IPOP had 12 operation modes. The main waveform is shown in Fig. 2. Key assumptions for the study:

(1) The dynamic and static characteristics of all devices are completely consistent,

(2) All the devices are ideal devices, neglecting the loss of the switching tube.

$$
C_{11}=C_{12}=C_{21}=C_{22}=C_{\text {lead }}
$$

$C_{13}=C_{14}=C_{23}=C_{24}=C_{\text {lag }}$,

(4) $L_{1} \gg L_{r 1} / k_{T 1}^{2}, L_{2}>L_{r 2} / k_{T 2}^{2}$,

$k_{T 1}$ and $k_{T 2}$ are the transformer ratio of the module 1 and 2 .

Mode 1[ $\left.t_{0}-t_{1}\right]$ : As shown in Fig. 1 and $2, \mathrm{~S}_{11}, \mathrm{~S}_{14}$, $\mathrm{S}_{21}$ and $\mathrm{S}_{24}$ are conducted. Module 1 provides energy to the inductance $\mathrm{L}_{1}$ through diode $\mathrm{D}_{11}$ and $\mathrm{D}^{14}$. The current of $\mathrm{L}_{1}$ increases linearly. Similarly, the current of $\mathrm{L}_{2}$ increases linearly. Blocking capacitor voltage of transformer primary vice side keeps on rising. The voltage of $\mathrm{C}_{11}, \mathrm{C}_{12}$ are as shown in the formula (1).

$$
\begin{aligned}
& U_{c 11}=-U_{c 11 m}+\frac{i_{T 1 p}}{C_{11}}\left(t-t_{0}\right) \\
& U_{c 12}=-U_{c 12 m}+\frac{i_{L 1}}{C_{12}}\left(t-t_{0}\right)
\end{aligned}
$$

Mode 2[ $t_{1}-t_{2}$ ]: $\mathrm{S}_{11}$ and $\mathrm{S}_{21}$ are turned off at the same time at $\mathrm{t}_{1}$ moment. $i_{T 1 p}$ and $i_{T 2 p}$ are respectively transferred from $\mathrm{S}_{11}$ and $\mathrm{S}_{21}$ to capacitance $\mathrm{C}_{\mathrm{s} 11}, \mathrm{C}_{\mathrm{s} 12}$ and $\mathrm{C}_{\mathrm{s} 21}, \mathrm{C}_{\mathrm{s} 22}$, while $\mathrm{C}_{\mathrm{s} 11}$ and $\mathrm{C}_{\mathrm{s} 21}$ are charged, $\mathrm{C}_{\mathrm{s} 12}$ and $\mathrm{C}_{\mathrm{s} 22}$ are discharged, $S_{11}$ and $S_{21}$ are zero voltage turn off. The vice side holds the operation mode of mode 1 . Due to the filter inductance $L_{1}, L_{2}$ and resonant inductance ${ }_{r 1}, L_{r 2}$ are in series, to assume that the $i_{T 1 p}$ and $i_{T 2 p}$ are unchanged, at the same time the voltage changes of parallel resonant capacitor are shown in the formula (2):

$$
\begin{gathered}
u_{c s 11}(t)=\frac{i_{T 1 p}\left(t_{1}\right)}{2 C_{\text {lead }}}\left(t-t_{1}\right) \\
u_{c s 12}(t)=V_{\text {in }}-\frac{i_{T 1 p}\left(t_{1}\right)}{2 C_{\text {lead }}}\left(t-t_{1}\right)
\end{gathered}
$$

At $\mathrm{t}_{2}$ moment, the voltage of $\mathrm{C}_{\mathrm{s} 11}$ and $\mathrm{C}_{\mathrm{s} 21}$ rise up to supply $V_{i n}$, the voltage of the $\mathrm{C}_{\mathrm{s} 12}$ and $\mathrm{C}_{\mathrm{s} 22}$ discharge to zero. Anti parallel diodes on $\mathrm{S}_{12}$ and $\mathrm{S}_{22}$ start to forward conduct. The voltage of $\mathrm{S}_{12}$ and $\mathrm{S}_{22}$ are clamped at zero by diode. The maintenance time of the state is shown in the formula (3):

$$
t_{21}=t_{2}-t_{1}=\frac{2 C_{l e a d} V_{i n}}{i_{T 1 p}}
$$

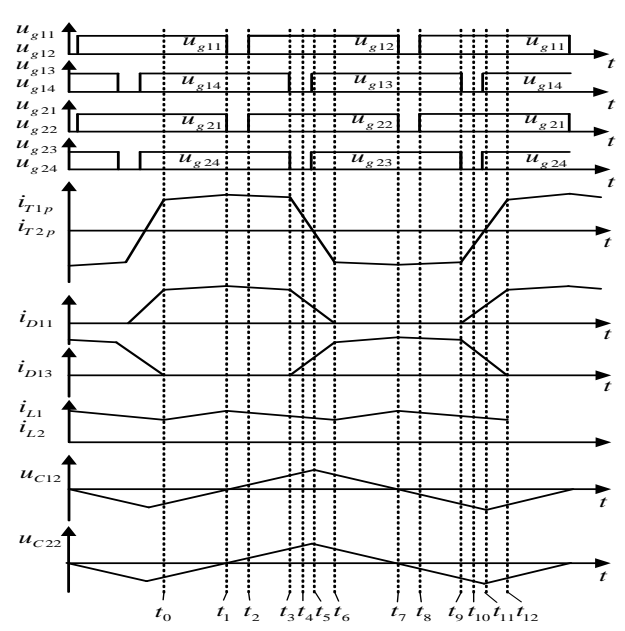

Figure 2. Waveform of the converter (SDC )

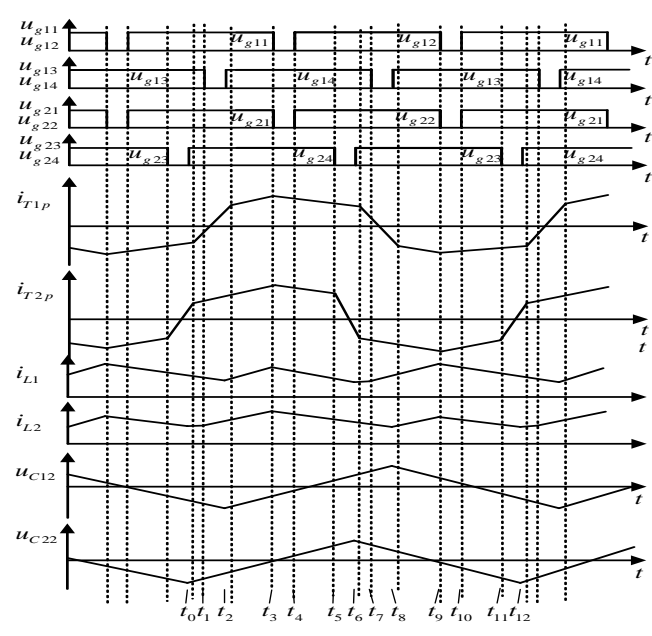

Figure 3. Waveform of the converter(DDC) 
Mode 3[ $t_{2}-t_{3}$ ]: $\mathrm{S}_{12}$ and $\mathrm{S}_{22}$ are driven at $\mathrm{t}_{2}$ moment, but the current on it's anti parallel diode is not zero. There is no current on $\mathrm{S}_{12}$ and $\mathrm{S}_{22}$. The blocking capacitor of primary vice side is charged by $L_{1}$.Meanwhile, the current of $L_{1}$ and the vice side current of transformer both decrease. Primary side current of transformer of module 1 is shown in the formula (4)and the current of module 2 is similar.

$$
i_{T 1 p}=\frac{i_{L 1}(t)}{k_{T 1}}
$$

Mode $4\left[t_{3}-t_{4}\right.$ ]: $S_{14}$ and $S_{24}$ are turned off at $t_{3}$, the primary side currents of transformer of two modules are respectively streaming through $\mathrm{C}_{\mathrm{s} 13}, \mathrm{C}_{\mathrm{s} 14}$ and $\mathrm{C}_{\mathrm{s} 23}, \mathrm{C}_{\mathrm{s} 24}$. At the same time, $\mathrm{C}_{\mathrm{s} 13}, \mathrm{C}_{\mathrm{s} 23}$ are discharged and $\mathrm{C}_{\mathrm{s} 14}, \mathrm{C}_{\mathrm{s} 24}$ are charged by the primary side current. Due to the existence of capacitance, $\mathrm{S}_{14}$ and $\mathrm{S}_{24}$ are zero voltage turned off. Assuming that the primary side currents are respectively $I_{T 1 p}$ and $I_{T 2 p}$, the vice side enters freewheeling, all the rectifier diodes begin freewheeling. Because the time is short, the voltage of primary side blocking capacitor is almost unchanged. It is also considered that the voltage on vice side blocking capacitor is approximately constant. At $\mathrm{t}_{4}$ moment, when the voltage on $\mathrm{C}_{14}$ and $\mathrm{C}_{24}$ rise up to $V_{\text {in }}$, the reverse parallel diode of $\mathrm{S}_{13}, \mathrm{~S}_{23}$ conduct. The maintenance time of mode 4 is shown (5):

$$
\begin{gathered}
t_{34}=\frac{1}{\omega_{1}} \arcsin \frac{V_{i n}}{Z_{1} I_{T 1 p}} \\
Z_{1}=\sqrt{L_{r 1} /\left(2 C_{l a g}\right)}, \omega_{1}=1 / \sqrt{2 L_{r 1} C_{l a g}}
\end{gathered}
$$

Mode $5\left[t_{4}-t_{5}\right.$ ]: The reverse parallel diodes of $\mathrm{S}_{13}$, $\mathrm{S}_{23}$ conduct at $t_{4}$ moment, meanwhile $\mathrm{S}_{13}, \mathrm{~S}_{23}$ may be able to conduction, which will be zero voltage conduction.

But there is no current through $\mathrm{S}_{13}$ and $\mathrm{S}_{23}, i_{T 1 p}$ is shown in the formula (6):

$$
i_{T 1 p}(t)=I_{T 1 p}\left(t_{4}\right)-\frac{V_{i n}}{L_{r 1}}\left(t-t_{4}\right)
$$

At $t_{5}$ moment, $i_{T 1 p}$ and $i_{T 2 p}$ decrease to zero, the reverse parallel diodes are turned off, the maintenance time of this state is shown in the formula (7):

$$
t_{45}=L_{r 1} I_{T 1 p}\left(t_{4}\right) / V_{\text {in }}
$$

Mode $6\left[t_{5}-t_{6}\right]$ : At $t_{5}$ moment, the current on primary side of transformer is zero-crossing. $S_{13}$ and $S_{23}$ begin to conduct and provide loop for transformer current. Since the primary side current is not sufficient to supply the current for load, the rectifier diodes of secondary stage are still freewheeling. When the winding voltage of transformer is approximately zero, the current on primary side of transformer of mode 1 is shown in the formula (8):

$$
i_{T 1 p}(t)=-\frac{V_{i n}}{L_{r 1}}\left(t-t_{5}\right)
$$

At $t_{6}$ moment, when $i_{T 1 p}$ rises up to the load current of transformer, this mode is over. At this moment, $\mathrm{D}_{11}, \mathrm{D}_{14}$ and $\mathrm{D}_{21}, \mathrm{D}_{24}$ are turned off, all the load current flow through $\mathrm{D}_{12}, \mathrm{D}_{13}$ and $\mathrm{D}_{22}, \mathrm{D}_{23}$. Module 1 provides energy to $L_{2}$ through $D_{13}$ and $D_{12}$. The current of $L_{2}$ increases linearly. Module2 provides energy to $\mathrm{L}_{1}$ through the diode $\mathrm{D}_{23}$ and $\mathrm{D}_{22}$, the maintenance time of mode 6 is shown in the formula (9):

$$
t_{56}=\frac{L_{r 2} I_{L 2}\left(t_{6}\right) / k_{T 2}}{V_{i n}}
$$

Modes 7-12[ $\left.t_{6}-t_{12}\right]$ : The operation from mode 7 to mode 12 are the same as the previous modes except the direction of powering path.

\section{B. Analysis of Equalizing Current with the Same Duty Cycles(SDC)}

By analyzing the working modes with SDC, it can be seen that $\mathrm{C}_{12}$ and $\mathrm{C}_{22}$ are charged when the transformer current is positive, and discharged when the current is negative. $\mathrm{L}_{1}$ and $\mathrm{L}_{2}$ is large enough, the current of capacitance can be assumed to change linearly. The charging and discharging time of the capacitance are all $T / 2$. The average currents of steady-state of $\mathrm{L}_{1}$ and $\mathrm{L}_{2}$ are $I_{L 1}$ and $I_{L 2}$. It can be concluded that the current in one cycle when the vice side blocking capacitor is steady as shown in the formula (10):

$$
\begin{gathered}
I_{c 12}=\left(T I_{L 1} / 2-T I_{L 2} / 2\right) / T \\
I_{c 22}=\left(T I_{L 2} / 2-T I_{L 1} / 2\right) / T
\end{gathered}
$$

The average current of capacitance in one cycle is zero, so the formula (11) can be obtained from the formula (10):

$$
I_{L 1}=I_{L 2}
$$


The output current auto-equalizing can be achieved by the transformer secondary side crossed rectification and vice side blocking equalizing-voltage capacitor.

\section{Analysis of Equalizing Current with the Different Duty Cycles(DDC)}

Duty cycles of the two modules are not identical when there are some differences among driving parts. Suppose the duty cycles of module 1 is $\mathrm{d}_{1}$, and module 2 is $\mathrm{d}_{2}$, and $\mathrm{d}_{2}$ is greater than $\mathrm{d}_{1}$. Also, assume that $\mathrm{S}_{24}$ is in the positive half cycle and $\mathrm{S}_{23}$ is in the negative half cycle conduct first. As shown in Fig. 3.

Mode 1[ $\left.t_{0}-t_{1}\right]$ : At $t_{0}$ moment, $\mathrm{L}_{2}$ is charged through $\mathrm{S}_{24}$ and $\mathrm{S}_{21}$, module 2 enters the positive half cycle first to provide energy for the load. The current flows through $\mathrm{S}_{21}$, primary winding of $T_{2}, \mathrm{~S}_{24}$ and to the negative of power supply. $S_{13}$ and the anti parallel diode of $S_{11}$ conduct streaming. ${ }^{L_{1}}$ begins the commutation stage first because of the inductance cross. This will make the circulation feedback time shorter, make module 1 to enter into the positive half cycle in advance, and reduce the difference of duty cycles. The simulation and experiments proved that each module could rapidly equalize current when there were parameter differences in duty cycles, internal resistance, inductance and so on.

\section{DESIGN OF THE EXPERIMENTAL PROTOTYPE}

The experimental prototype of $20 \mathrm{~kW}$ based on IPOP-PSFB combination converter was developed in this paper. The parameters is shown in table 1. The parameters design and device selection of each module can refer to the basic PSFB.

TABLE I. MAIN CIRCUIT PARAMETERS

\begin{tabular}{|c|c|c|c|c|}
\hline $\mathrm{U}_{\text {in }}$ & $\mathrm{U}_{0}$ & $\mathrm{i}_{0}$ & $\mathrm{f}$ & \\
\hline $530[\mathrm{~V}]$ & $0 \sim 1000[\mathrm{~V}]$ & $0 \sim 20[\mathrm{~A}]$ & $50[\mathrm{kHz}]$ & \\
& & & & \\
\hline $\mathrm{L}_{\mathrm{r} 1} / \mathrm{L}_{\mathrm{r} 2}$ & $\mathrm{~L}_{1} / \mathrm{L}_{2}$ & $\mathrm{C}_{12} / \mathrm{C}_{22}$ & $\mathrm{C}_{0}$ & $\mathrm{C}_{11} / \mathrm{C}_{21}$ \\
\hline $20[\mathrm{uH}]$ & $1[\mathrm{mH}]$ & $1[\mathrm{uF}]$ & $2[\mathrm{uF}]$ & $4[\mathrm{uF}]$ \\
& & & & \\
\hline
\end{tabular}

\section{ANALYSIS OF EXPERIMENT AND SIMULATION}

\section{A. Analysis of Pspice Simulation}

These IPOP-PSFB were studied in Pspice environment. When $d_{1}=50 \%, d_{2}=55 \%$. the simulation results are shown in Fig.4, the direct parallel figure is shown in 4(a), the filter inductance currents of the two module have a current difference when there is load change. After entering the steady state again, the current difference is $\Delta I=2.5 \mathrm{~A}$. The cross parallel figure is shown in 4(b), the filter inductance currents of the two module are almost same and it can realize automatic equalization current when there are other less than $10 \%$ parameters difference such as resistance and inductance.

\section{B. Experimental Research of AEC when the Parameters are Different}

In order to simulate the difference of internal resistance, $0.5 \Omega$ resistance is in series at rectifier output of the diode in the module 1. As shown in Fig.5(a), The L1/L2 current waves are basically the same and the output error is $0.2 \mathrm{~A}$, current sharing

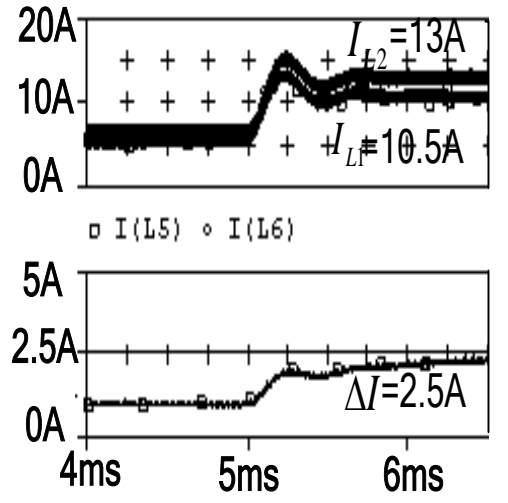

(a) Direct parallel
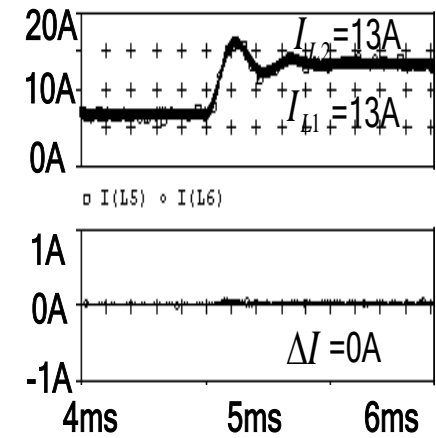

(b) Cross parallel

Figure 4. The L1/L2 current when the duty ratio is different. 


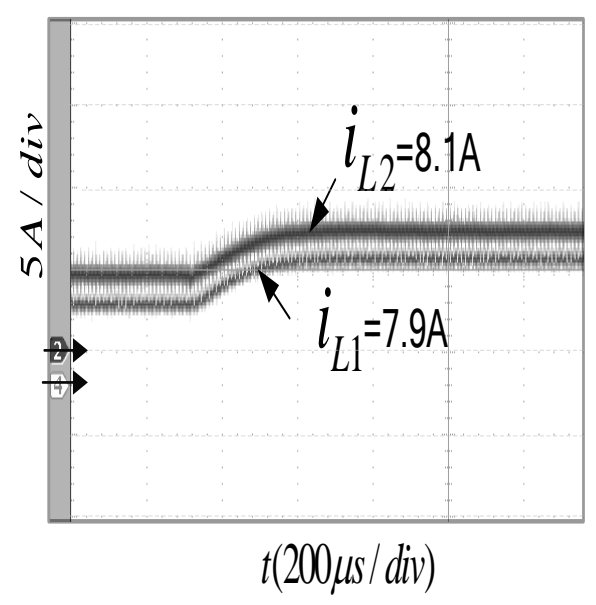

(a) R is not consistent

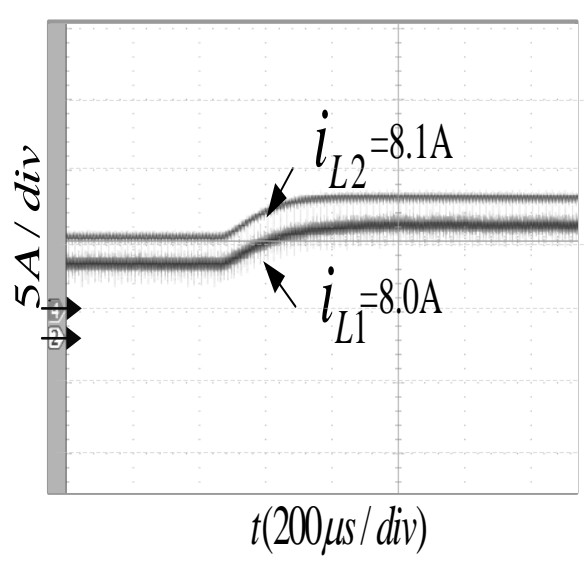

(b) Duty ratio is not $\mathrm{C}$

Figure 5

The L1/L2 current waves

error is $1 \%$ and the load current of $16 \mathrm{~A}$ is averaged. The dynamic changes are almost the same for the two modules when the load current changes from 10A to 16A.

When the duty cycles are not consistent ( $d_{1}=50 \%, d_{2}=55 \%$ ), As shown in Fig.5(b), The current error at steady-state is $0.1 \mathrm{~A}$. The current sharing error is $0.7 \%$ and the current of the two inductance are also consistent with the dynamic change.

The experiments were set up to prove that the power supply prototype could realize dynamic and steady state equalizing current rapidly with the difference of duty ratio, internal resistance, and inductance in each module.

\section{CONCLUSION}

The transformer secondary side crossed rectification was applied to BPSMS based on IPOP-PSFB to meet the requirements of high voltage and large current output. The bias power supply could realize current AEC and the soft switch was achieved also. The $20 \mathrm{~kW}$ experimental prototype was made, the output voltage and current were $0 \sim 1000 \mathrm{~V}, 0 \sim 20 \mathrm{~A}$. The power supply could well meet the requirements in the field of magnetron sputtering, high efficiency, low cost, and the design method is simple.

\section{REFERENCES}

[1] Huang Y, Tse C K. Circuit theoretic classification of parallel connected DC-DC converters, Circuits and Systems I: Regular Papers, IEEE Transactions on.54(5): 1099-1108. (2007)

[2] ZHANG Jun-ming,XIE Xiao-gao,W Xin-ke,QAIN Zhao-ming.RESEARCH ON ACTIVE CURRENT-SHARING METHODS FOR DC/DC CONVERTERS, Proceedings of the CSEE. 19:31-36. (2005)

[3] ZHOU Ling-bin, Research on Automatic Current and Voltage Sharing of High Frequency Combined DC-DC Converters. Zhejiang University.(2012) .In Chinese

[4] CAO Zhen-en, GONG Chun-zhi, TIAN Xiu-bo, YANG Shi-qin. VACUUM.02:70-73. (2008) .In Chinese

[5] CHENG Juan. Study on the Cross Rectifier Combined DC-DC Converter with the Input-parallel Output-parallel Connected. Zhejiang University.(2013). In Chinese 